The following document is a pre-print version of:

Bourke A, Ross P-S (2016) Portable X-ray fluorescence measurements on exploration drill cores: comparing performance on unprepared cores and powders for "whole-rock" analysis. Geochemistry: Exploration, Environment, Analysis 16:147-157

\title{
Portable X-ray fluorescence measurements on exploration drill-cores: comparing performance on unprepared cores and powders for 'whole-rock' analysis
}

\author{
A. Bourke \& P. -S. Ross \\ Institut national de la recherche scientifique, centre Eau Terre Environnement, 490, rue de la Couronne, Québec \\ (QC), G1K 9A9, Canada \\ rossps@ete.inrs.ca
}

\begin{abstract}
One geoscience application of pXRF technology is acquiring 'whole-rock' analyses of unmineralized or weakly mineralized rock cores for major oxides and trace elements, to fill the gaps between traditional laboratory analyses and/or obtain geochemical data more quickly. But the question of whether the samples actually need to be crushed and pulverized before analysis to produce useful results has not been extensively studied. In this paper pXRF data quality is compared on unprepared rock cores and on powders in three ways: instrumental precision (relative standard deviation, RSD, of a series of measurements on the same spot), sample precision (for unprepared samples, RSD of a series of measurements on different spots on the core), and accuracy (average pXRF value versus laboratory geochemistry). Two Olympus Innov-X Delta Premium pXRF devices were tested on 27 core samples of dense, non-mineralized, fine- to medium-grained, Precambrian volcanic and intrusive rocks from Canada. In general, sample preparation does not improve instrumental precision or accuracy. The significant advantage of powders is to avoid mineralogical heterogeneity. However sample precision for in situ data is improved by averaging multiple measurements of different points on the sample: a significant gain is obtained between three and seven measurements. The sample precisions at 25 points - which is about the most measurements one can make during the same amount of time used for powdering a rock core sample - are better than the instrumental precision on powders for most elements. For high spatial resolution downhole element profiles on entire drill holes, in situ pXRF measurements with smoothing (e.g. three to five point moving averages) provide fit-forpurpose data; the alternative of turning the entire drill-core into powder is not realistic..
\end{abstract}

\section{INTRODUCTION}

Diamond drilling is a major component of advanced mining exploration programs. Two types of traditional laboratory geochemical analyses are often performed on exploration drill-cores by the mining industry, geological surveys and university researchers: (1) assays of mineralized or potentially mineralized samples, for elements such as base metals, precious metals, rare earth elements, etc. (e.g. Moon et al. 2006); and (2) 'whole-rock' analyses of unmineralized or weakly mineralized samples for major oxides and trace elements (e.g. Ross 2010; Mercier-Langevin et al. 2014; Rogers et al. 2014). The first type of analysis is carried out within selected intervals, often on $c .1 \mathrm{~m}$ long sections of split or cut cores, to quantify the grades of orebodies. The second type of analysis can be used for improving lithological discrimination (e.g. Rogers et al. 2014) and quantifying hydrothermal alteration (e.g. Mercier-Langevin et al. 2014), for example, but is not always performed, and is normally done on pieces of core a few dm-long, using a wide sampling interval such as $10 \mathrm{~m}$ to $50 \mathrm{~m}$, due to high analytical costs. Though the results of such analyses are normally precise and accurate, the time between choosing the sample and obtaining the results can be long (weeks to months).

Recent technological developments have allowed complementary geochemical analyses to be performed in situ (on unprepared rock samples or other materials) or on powders using portable X-ray fluorescence (pXRF) devices. The smallest of those analysers are handheld analysers. These can detect and 
quantify about 25 elements in a few minutes by nondestructive means, and the spatial resolution can go down to a few centimetres if needed (Analytical Methods Committee 2008). They can be used for various applications, including forensics (e.g. Trombka et al. 2002), archaeology (e.g. Nazaroff et al. 2010) and mineral exploration. In the latter field, the focus so far has been on analysing pulverized rock samples (Gazley et al. 2011) or performing the equivalent of assays on drill-cores (Glanzman \& Closs 2007; Peter et al. 2009; Fajber \& Simandl 2011; Marsala et al. 2011). Ross et al. (2014a, 2014b) have also looked at performing, in situ, the equivalent of whole-rock analyses on drillcores to produce high spatial-resolution elemental profiles.

It is common in the literature to crush and pulverize rock samples before analysing them with a pXRF device (e.g. Figueroa et al. 2011; Hall et al. 2013a; Fischer et al. 2014; Le Vaillant et al. 2014; Piercey \& Devine 2014). However, preparing a powder before analysis is labour- and time-consuming, and it requires space and specialized equipment in the core shack. The biggest advantage, obviously, is that powdered samples are much more homogeneous than unprepared rocks. But does that disqualify in situ measurements, and what is the influence of the sample preparation on precision and accuracy? Hall et al. (2003b) tested a variety of rocks and ores, in terms of composition and grain size, in both unprepared and powdered form, and concluded that "one can expect a large deterioration in precision (RSD) in the direct analysis compared to the powder, obviously depending on the homogeneity and mineralogy of the sample for that element; the magnitude of this deterioration varies enormously, from about fourfold to fortyfold". For fine-grained samples, however, averaging 1-3 in situ measurements tended to produce usable results $(10 \%$ errors or less) in that study (their table 4.3), suggesting a need for further investigation before a systematic recommendation to pulverize all samples is made. In particular, if the intention is to obtain high spatial resolution downhole elemental profiles on entire drill holes, could in situ pXRF measurements with smoothing be acceptable?

Another concern that appears in many technical studies of pXRF is potential instrumental drift during a series of measurements (Arne et al. 2014, Fischer et al. 2014, Hall et al. 2013a, 2014, Le Vaillant et al. 2014, Piercey \& Devine 2014). To counter this potential problem, the most common strategy is to analyse CRMs (Certified Reference Materials) periodically to monitor any drift and correct it (Fisher et al. 2014, Hall et al. 2014, Le Vaillant et al. 2014). Such strategies can become time consuming and Fischer et al. (2014) and Simandl et al. (2014) noticed negligible drift, leading to doubts about the necessity of investing substantial time on measuring CRMs every hour or every 20 samples.

This paper, building on the work of Ross et al. (2014a, 2014b), continues the performance study of two pXRF analyzers used on non-mineralized to weakly mineralized rock core samples. The main focus here is on comparing the performance of the devices on a series of rock core samples, both in situ and in powdered form. Instrumental precision, sample precision (the effect of sample heterogeneity: Le Vaillant et al. 2014) and accuracy are examined. In addition the issue of instrumental drift is briefly discussed.

\section{METHODS}

Instruments

Institut national de la recherche scientifique (INRS) owns two identical Delta Premium analysers from Olympus Innov-X of Woburn, Massachusetts, called informally 'Delta-A' and 'Delta-B'. When working on rock cores, the analysers are attached to laboratory stands, so they are not actually handheld. Each device can be set to a specific analysis mode: 'soil' or 'mining plus'. The soil mode is calibrated for low concentrations $(<2$ wt. \%), although it can yield satisfactory results at higher concentrations for some elements, like $\mathrm{Fe}$ and $\mathrm{Ca}$, on rock samples. Three different X-ray beams are used in this mode, and the analysis is based on Compton normalization (Jenkins 1999; Innov-X Systems Inc. 2010; Hall et al. 2013a). The mining plus mode, in contrast, is calibrated to measure high concentrations ( $>2 \mathrm{wt} . \%$ ) and is the only mode measuring the light elements $\mathrm{Al}, \mathrm{Mg}$ and $\mathrm{Si}$. It also gives information on lower concentration elements, like $\mathrm{Cr}, \mathrm{Zn}$ and $\mathrm{Zr}$, for rock samples. This mode has only two beams and the analysis is based on 'fundamental parameters' (Jenkins 1999; Innov-X Systems Inc. 2010; Hall et al. 2013a). The soil mode was assigned to the Delta-A device and the mining plus mode was assigned to the Delta-B device in order to minimize calibration problems and to avoid constantly switching between modes. In routine logging, each sample is analysed separately with the two devices, on the same spot.

\section{Instrumental drift}

Both analysers were tested for short term variations (intra-day) and long term variations (over a year). For short term drift, a single NIST standard was measured with each instrument (NIST $2780^{1}$ for the Delta-A and NIST $2702^{2}$ for the Delta-B) continuously for several

\footnotetext{
${ }^{1}$ Hard rock mine waste; the certified composition can be found at https://www-s.nist.gov/srmors/view_detail.cfm?srm=2780

${ }^{2}$ Inorganics in marine sediment; the certified composition can be found at https://www-s.nist.gov/srmors/view_detail.cfm?srm=2702
} 
hours. Results were normalized to the first measurement before calculating a nine-points moving average, discarding the four first and four last results from the graphs. The smoothing is done to decrease the effect of instrumental precision and focus on visualizing drift, if any. For studying long term drift the same NIST standard/pXRF analyser combination was used. A series of 10 consecutive measurements were made every few months, after a 'warm-up' period of at least an hour, over a total period longer than one year, for a total of six series. The results of each series were averaged for each element and normalized on the average of all measurements.

Choice of samples for precision and accuracy determinations; traditional geochemistry data

For the seven Matagami rock core samples, ranging in composition from gabbro to rhyolite, used by Ross et al. (2014a) to perform in situ measurements in mining plus mode, a representative fraction of the rejects - the unused coarsely crushed material from traditional geochemistry - were pulverized (see details below) and analysed in the mining plus mode only.

Twenty additional Abitibi drill-core samples (BQ and NQ calibre) were used in this study to increase the number of data points on calibration graphs; for these 20 samples, measurements were made in situ in both modes, and on equivalent powders in both modes, as explained below. The additional Abitibi samples were chosen from the INRS collections: 10 from the Lake Hébécourt region (Blake River Group near Rouyn-Noranda, Quebec) and 10 from the Lemoine mine area of the Chibougamau region (Quebec). The following criteria were used for sample selection: hydrothermal alteration had to be low; the proportion of disseminated sulphides had to be minimal; sample lengths had to be at least $15 \mathrm{~cm}$; and a range of lithologies (from mafic to felsic) had to be represented. After the in situ pXRF measurements had been taken, the 20 samples were sent to Activation Laboratories Ltd (Ancaster, Ontario) for pulverization $(<106 \mu \mathrm{m}$; code RX2) and geochemical analysis by fusion ICP-AES, fusion ICP-MS and total digestion ICP-MS (code 4LITHORES + 4B1).

\section{Sample preparation for $\mathbf{p X R F}$ analysis of powders}

For the 20 Hébécourt and Chibougamau samples, the pulverized fraction returned by Activation Laboratories was used for pXRF analysis. For the seven Matagami samples, only the coarsely crushed ['nominal minus 10 mesh $(1.7 \mathrm{~mm})$ '] rejects were available, so additional powder was generated. A representative portion of the rejects was pulverized in a mild steel 'shutter box' for 3 minutes at INRS. The average grain size is estimated to be c. $100 \mu \mathrm{m}$, similar to the powders returned by Activation Laboratories.

All powders were placed in cylindrical XRF sample cups, $2.2 \mathrm{~cm}$ high and $3 \mathrm{~cm}$ in diameter, covered with a $6 \mu \mathrm{m}$-thick Mylar ${ }^{\circledR}$ film. This particular film is tear-resistant but has been shown to have low Xray transmittance for light elements such as $\mathrm{Si}, \mathrm{Mg}$ and Al (Hall et al. 2013a); the authors of this paper were not aware of this problem when they used these films. The internal capacity of the cups is a cylinder $1.8 \mathrm{~cm}$ high with a diameter of $2.6 \mathrm{~cm}$; they were fully filled with powder and the Mylar ${ }^{\circledR}$ film was in direct contact with the powder.

\section{Instrument performance}

Ross et al. (2014a) describe instrumental precision and beam time testing on a sediment standard using both modes of analysis. They also report on a similar test on rock cores, in situ, using the mining plus mode only. Here in situ tests are expanded to the soil mode using the Delta-A analyser. From the 20 new samples, one basaltic andesite (HEB-02-08) and one rhyolite (MD01-01) were selected. For the beam time optimisation, 31 continuous measurements on a single spot of each core sample were performed at various integration times, namely 10, 15, 20, 30 and 40 seconds per beam (there are 3 beams in soil mode). Relative standard deviation (RSD) was calculated for each element for each sample. The RSD also serves to evaluate instrumental precision at the chosen beam time. For powdered samples in XRF cups, the RSD of 31 continuous measurements on the same spot of each sample was calculated.

Accuracy of in situ measurements on core samples was assessed by comparing pXRF data with traditional laboratory geochemistry. Each core sample had its entire surface covered with 31 to $63 \mathrm{pXRF}$ measurements, depending on the sample length, with both analysers. Measurements were then averaged for each sample to yield a representative pXRF composition, which can be compared with traditional geochemistry. The accuracy plots for the mining plus mode also integrate the seven Matagami samples described by Ross et al. (2014a). Accuracy on powdered samples was assessed the same way: 31 measurements were averaged for each sample and plotted against traditional geochemistry.

The data acquired to assess accuracy can also be used to determine sample precision, i.e. the effect of mineralogical heterogeneity on in situ pXRF measurements. Another way to define sample precision is the reproducibility of multiple analyses on different points (Le Vaillant et al. 2014). This is simply done by calculating the RSD of the 31-63 spots for each element and each sample. This sample precision can 
then be directly compared to the analytical precision on intact cores or on powders, for the same sample.

\section{RESULTS \\ Instrumental drift}

Figure 1a shows the results of the short term drift test on a NIST standard for selected elements determined by device B. Most elements show a flat trend demonstrating the absence of instrumental drift within a day. There are some variations in the results, but they are within the instrumental precision of each element. However, it was noticed that if the $\mathrm{pXRF}$ analyser has not been used for several weeks, significant variations occurred over an initial period of 30 to 60 minutes, before stabilizing. To avoid this, a 'warm up' of about one hour is recommended, where the analyser is running continuously, after prolonged periods of no use. No such warm-up periods are included in Figure 1a. Although this study did not encounter troublesome instances of intra-day drift, cases were noted by Hall et al. (2013a), so pXRF users should ascertain whether or not their particular instrument is subject to intra-day drift.

Figure $1 \mathrm{~b}$ shows the results of the long term drift test. Over a period of 13 months, most elements show a flat trend through the graph, implying that there was no drift over this period, although some elements, namely $\mathrm{K}, \mathrm{Al}$ and $\mathrm{Si}$, show a slight negative tendency. It is not obvious that this is actually an instrumental drift, as the variations are no more than $\pm 5 \%$ relative..These results are reassuring but the behaviour could change as the instruments become older.

\section{Beam time on rock cores (in situ), soil mode, Delta- A device}

The RSD of each series of 31 measurements is used to assess instrumental precision of the Delta-A device in soil mode, on rock cores (in situ), for different beam times, using a rhyolite (Fig. 2) and a basaltic andesite (Fig. 3). For the rhyolite, the RSDs of the major elements detected in 'soil' mode are $4 \%$ or less, thus the precision is very good, for 15 seconds per beam or longer times (Fig. 2a), whereas the RSDs for trace elements is more variable, ranging from less than $2 \%$ for $\mathrm{Y}$ and $\mathrm{Zr}$ (for long beam times) to more than $20 \%$ for $\mathrm{Cu}$ (Fig. 2b). The gain in precision seems to be limited beyond 20 to 30 seconds per beam for most trace elements. In the basaltic andesite, the precision for major elements is also very good (Fig. 3a), except for $\mathrm{K}$ which occurs in low concentration in this sample (see Table 1). For trace elements in the basaltic andesite, there is only a slight lowering of the RSD beyond $30 \mathrm{~s}$ per beam for the elements $\mathrm{Zr}, \mathrm{Y}, \mathrm{Sr}, \mathrm{Zn}$ and $\mathrm{V}$ (Fig. 3b). Thus, the optimal beam time for routine in situ logging is $c$. $30 \mathrm{~s}$ per beam, both in mining plus mode (Ross et al. 2014a) and in soil mode (this study).

\section{Instrument performance on rock cores and on powders}

Instrumental precision: the following elements have an RSD of less than $4 \%$ for both rock cores and powdered samples: Ti, Fe, Mn, $\mathrm{Ca}, \mathrm{Sr}, \mathrm{Y}$ and $\mathrm{Zr}$ (Table 1). Comparison of precision for the two media shows that the instrumental precision of pXRF measurements is typically similar for in situ measurements vs. powders. In fact, when measuring a powdered sample, the precision deteriorates slightly for at least one sample for almost all elements, and is significantly worse for $\mathrm{Cr}$ in the basaltic andesite. Furthermore, $\mathrm{K}$ and $\mathrm{Cu}$ were detected on both core samples, but in powders $\mathrm{K}$ was only detected in the rhyolite whereas $\mathrm{Cu}$ was only detected in the basaltic andesite, these samples containing the higher concentrations of the said elements. This suggests that for these elements, the detection limit may be higher on powders than for in situ measurements. However, powders do provide a better instrumental precision for $\mathrm{Cu}$ (5.6\% RSD vs. $10.8 \%$ ) in the basaltic andesite.

Accuracy and correction factors: the averaged pXRF concentrations for both analysers and both media, and traditional geochemical analyses of each sample used for this study, are shown in online supplementary tables S1 to S5. For each element, each medium and each sample, the accuracy of the pXRF measurements is the normalized difference between the pXRF averages and the laboratory geochemistry value. Overall accuracy for each element can be evaluated using the linear regressions ${ }^{3}$ in figures 4 and 5. Every graph illustrates the two media: intact rock cores (blue triangles) and powders (pink squares). From these graphs, a linear regression equation and a coefficient of determination $\left(\mathrm{R}^{2}\right)$ were calculated for each media and each element.

When the $\mathrm{R}^{2}$ is higher than $c .0 .9$, the pXRF data can be corrected with the reverse of the linear regression, for this particular suite of samples and these particular analysers. Two exceptions were made for $\mathrm{SiO}_{2}$ and $\mathrm{Al}_{2} \mathrm{O}_{3}$ ( $\mathrm{R}^{2}$ of 0.88 and 0.82 , respectively, on rock cores) because those elements are important to our work. Also, even though the scatter of the results is quite large, there is a clear linear trend for both these

\footnotetext{
${ }^{3}$ The linear regressions in Ross et al. (2014a) were forced through the origin. But as suggested by Hall et al. (2014), the new linear regressions presented here were not forced to the origin. The fit $\left(\mathrm{R}^{2}\right)$ of those regressions is thus better for all the elements. Also, Hall et al. (2014) use a regression technique called the maximum-likelihood functional relationship (MLFR) estimation instead of a linear regression because it takes account of the measurements error and it is nearly statistically unbiased (Ripley \& Thompson 1987). However there is no advantage to use this method if the errors are assumed to be associated with the y axis only, as was done here.
} 
elements, so one should remain flexible on the $\mathrm{R}^{2}$ cutoff. The correction factors are listed in Tables 2 and 3 for the soil and mining plus modes, respectively, for in situ work. The factors in Table 3 are different from those presented by Ross et al. (2014a) for the same analyser in the same mode since 20 samples were added to the plots. The following elements and oxides are correctible: $\mathrm{Al}_{2} \mathrm{O}_{3}, \mathrm{CaO}, \mathrm{Cr}, \mathrm{Fe}_{2} \mathrm{O}_{3}, \mathrm{~K}_{2} \mathrm{O}, \mathrm{MgO}$, $\mathrm{MnO}, \mathrm{Nb}, \mathrm{Ni}, \mathrm{Rb}, \mathrm{SiO}_{2}, \mathrm{Sr}, \mathrm{TiO}_{2}, \mathrm{Y}$ and $\mathrm{Zr}$. In contrast, $\mathrm{P}_{2} \mathrm{O}_{5}, \mathrm{~S}$ and $\mathrm{V}$ are judged to be not correctible, because the results are too scattered to show any linear trend. The poor results can be caused by low concentrations in the samples, not enough data available, matrix effects, interferences, or miscalibration of the pXRF devices.

Now the question is whether powders are preferable to in situ measurements in term of accuracy. Note that this assessment compares measurements done on different spots and averaged, for in situ data, with the mean of a series of measurements on the same spot, for powders. This way, only the accuracy is involved in the comparison, not the mineralogical heterogeneity of the sample. On figures 4 and 5, the closer the linear regression is to the $1: 1$ dotted line, the better the accuracy is. For example, looking at $\mathrm{K}_{2} \mathrm{O}$, the equations of the linear regressions and the $\mathrm{R}^{2}$ are very similar for both media (Fig. 4a). In contrast, for $\mathrm{Cu}$, the slope is nearer to one and the $\mathrm{R}^{2}$ much higher for the powders (Fig. 4d). Finally, for $\mathrm{Al}_{2} \mathrm{O}_{3}$, the performance is clearly better in situ (Fig. 5a). So among the correctible elements, three groups can be proposed with regards to the accuracy of pXRF measurements on rock cores vs. powders: the elements or oxides better analysed on rock cores, those better analysed on powders, and those which show similar results (Fig. 6).

The first group, the elements better analysed on rock cores, includes $\mathrm{Al}, \mathrm{Mg}$ and $\mathrm{Si}$ - the three lightest elements ${ }^{4}$. The relatively thick Mylar ${ }^{\circledR}$ films used on sample cups in this study were clearly a factor to explain the poor performance on powders (Hall et al. 2013a). Also, powders contain more air than unprepared rock cores. Those "barriers" could have attenuated the incident X-ray beam or the fluorescent photons, especially the low energy photons, which are needed to analyse the light elements (Shackley 2011). Further testing on light elements in rock powders should be done with plastic films causing less attenuation. The second group of elements, those that are better analysed on powders, includes $\mathrm{Cu}$ and $\mathrm{Zn}$

\footnotetext{
${ }^{4}$ For the three cases, the slope of the linear regression is closer to 1 and the $\mathrm{R}^{2}$ is greater for the analyses on rock cores. For $\mathrm{MgO}$, the trend of the powder dataset is almost flat, with a slope of less than 0.17 . Finally, for the three cases, the pXRF values on powders are greatly underestimated compared to the laboratory geochemistry.
}

(Figs. 4d, 4e $)^{5}$. This behaviour can probably be explained by the heterogeneity of the rock cores. In the studied samples, $\mathrm{Zn}$ and $\mathrm{Cu}$ are generally contained in sulphides disseminated in the rock. When attempting to cover the surface of the core with in situ pXRF analyses, the average of the results can be greatly affected by how many sulphide grains were analysed. In other words, for $\mathrm{Cu}$ and $\mathrm{Zn}$ at low concentrations, the element distribution in the sample is so heterogeneous that even 30-50 measurement points are not enough to average out the 'nugget effect'; this is not a problem for other elements. The third group, the elements and oxides showing similar results regardless of the media, includes $\mathrm{CaO}, \mathrm{Cr}, \mathrm{Fe}_{2} \mathrm{O}_{3}, \mathrm{~K}_{2} \mathrm{O}, \mathrm{MnO}, \mathrm{Ni}$, $\mathrm{Nb}, \mathrm{Rb}, \mathrm{Sr}, \mathrm{TiO}_{2}, \mathrm{Y}$ and $\mathrm{Zr}$. There would be no significant gain on the accuracy of the data by pulverizing rock cores to determine those elements (Fig. 6).

Limits of detection on rock cores: also included in Tables 2 and 3 is a rough estimate of the limit of detection for each corrected element based on the second smallest value ${ }^{6}$ for each element in our full pXRF database containing thousands of measurements on Archean volcanic and intrusive rocks, for the Matagami region (Ross et al. 2012) and the Chibougamau region (Ross et al. 2014c).

\section{Sample precision for in situ data}

Sample precision is presented in Table 4 for one representative core sample (the equivalent results for other samples are available upon request). Sample precision is obviously worse than analytical precision on intact rock cores: this is the effect of sample heterogeneity. For example, in situ instrumental precision is better than $2 \%$ for $\mathrm{Ti}$ but the sample precision is seven times worse. Thus most of the scatter on downhole elemental plots is due to sample heterogeneity, not instrumental precision. However, the in situ data can be smoothed to attenuate this effect as discussed below.

\section{DISCUSSION}

It is common practice in the literature to crush and pulverize rock samples before analysing them with a pXRF device. However, preparing a powder before analysis is labour- and time-consuming. This study shows that the instrumental precision and the data accuracy are not generally improved with powdered

\footnotetext{
${ }^{5}$ It is clear for $\mathrm{Cu}$ that the analyses on powders are better, since the slope of the linear regression is much closer to one and the $\mathrm{R}^{2}$ is much higher. For Zn, the two linear regressions might appear similar at first glance, but the rock core dataset contains more outliers than the powder dataset, which decrease dramatically the $\mathrm{R}^{2}$ for the former.

${ }^{6}$ The Innov-X software does not report values which it judges to be below the limit of detection.
} 
samples, relative to in situ pXRF measurements, with a few exceptions. The key advantage of the powder is therefore to homogenize the sample: in situ measurements are heavily influenced by mineralogical heterogeneity, even for our fine- to medium-grained samples (e.g., Table 4). However, assuming that a high spatial resolution downhole geochemical profile is desired (e.g.. 20-40 cm measurement spacing), working on powders would mean the near total destruction of the core, which may not be allowed by the owner. Or if time is a limiting factor, there would be a loss of spatial resolution.

The effect of mineralogical heterogeneity is decreased when several in situ measurements are taken next to each other on a sample and averaged (Hall et al. 2013b). To explore this further the basaltic andesite sample (HEB-02-08) covered by device A in soil mode with 42 measurements spread over its surface is taken as an example. Moving averages of 3 to 29 points were calculated for all the elements. The RSDs were plotted against the number of points in each moving average in Figure 7. For example, if one averages five measurements taken at different points on the core sample, the result for Fe should be within $\pm 10 \%$ of the average of 42 measurements, two-thirds of the time (Fig. 7a). For most elements, the main gain in sample precision is achieved within 3 to 7 measurements, except for the elements in low abundances in this sample, such as $\mathrm{K}$ and $\mathrm{Zn}$. Using the suggestion of Piercey \& Devine (2014) for precision qualification (excellent precision is $<3 \%$; very good is $3-7 \%$; good is $7-10 \%$; poor is $>10 \%$ ), all elements, even the less abundant ones, have 'good' or better precisions at 17 measurements.

Suppose that 40 minutes is available to fully characterize one core sample with two pXRF analysers (one in soil mode, the other in mining plus mode). During this time, a single qualified person can either make 25 in situ analyses with both analysers on the sample $^{7}$, or spend much of the time crushing the sample, quartering to obtain a repetitive fraction, pulverizing, cleaning the equipment, putting the powder into a XRF cup, and performing a single measurement with each analyser. In Table 4 one can directly compare the sample precision of the 25 point averages for in situ work with the instrumental precision for the powder. The in situ results are comparable or better for most elements. Only with $\mathrm{Fe}$ and $\mathrm{Ca}$ the powder is considerably better, but the in situ precision for these elements are still considered excellent.

\footnotetext{
${ }^{7}$ With a batch of samples being processed sequentially, the analysers can run simultaneously and each take 20 to 25 measurements on every sample during the allocated $40 \mathrm{~min}$.
}

Instead of taking measurements close together on a core sample and average them, it is possible to take measurements at regular intervals along the core and smooth the data with a 3-point or 5-point moving average (Ross et al., 2013, 2014b). This assumes that geological units are much thicker than the measurement interval, which would typically be the case for lava flows or thick sills for example.

\section{CONCLUSIONS}

This study compared in situ pXRF measurements on drill cores with measurements on equivalent powders for a suite of 27 samples of dense, fine- to mediumgrained, mafic to felsic, non-mineralized, Precambrian volcanic and intrusive rocks from the Abitibi Greenstone Belt of Canada. Instrumental drift was also assessed. It was shown that:

1. intra-day or long-term instrumental drift does not seem to be a common problem;

2. in general, there is no gain in instrumental precision by analysing powders instead of unprepared rock cores;

3. in general, powdering does not lead to significant gains in accuracy either;

4. for both media (rock cores or powders), data accuracy can be dramatically improved by applying analyser-specific and matrix-specific corrections factors derived from regression of the pXRF data against traditional laboratory geochemistry on the same suite of representative samples.

Powdering is a good way to counter mineralogical heterogeneity and is the main justification for sample preparation, but it destroys the drill core and is time-consuming. This study confirms that on fine- to medium-grained volcanic and intrusive rocks, averaging multiple measurements on different spots on the sample will quickly improve sample precision to acceptable levels for most geological applications. For example, if the goal is to obtain highspatial resolution downhole geochemical profiles on entire drill holes, then in situ measurements with smoothing (e.g. three to five point moving averages) provide fit-for-purpose data (Ross et al. 2013, 2014b).

\section{ACKNOWLEDGEMENTS}

Equipment purchase was funded by the Canadian Foundation for Innovation, the government of Quebec (ministère de l'Éducation, du Loisir et du Sport) and Fonds québécois de recherche sur la nature et les technologies (FQRNT). Initial work with the analysers was performed using research funding from Ministère des Ressources Naturelles et de la Faune (Québec) and FQRNT. Xstrata Zinc Canada (now Glencore plc), Donner Metals Ltd. and Breakwater Resources (now NyrStar) provided access to cores and logistical support 
in Matagami. Ressources Cogitore Inc. and Forages Chibougamau provided access to cores and logical support in Chibougamau. All of these organizations are thanked and especially the following individuals: $M$. Allard, M. Dessureault, S. Lacroix, F. Lefebvre, S. Lépine, G. Riverin, and G. Roy. Samples were collected by R. Rogers (Lake Hébécourt region) and S. Cioldi (Chibougamau region). Data acquisition was made with the help of B. Fresia, P. Nguyen and J.-P. Pomerleau. Discussions with P. Mercier-Langevin led to the idea of using pXRF analysers to obtain geochemical profiles on drill-cores. G. Hall and G. Bonham-Carter are thanked for useful journal reviews.

\section{REFERENCES}

Analytical Methods Committee, Royal Society of Chemistry, 2008. Evaluation of analytical instrumentation. Part XXIII. Instrumentation for portable X-ray fluorescence spectrometry. Accreditation and Quality Assurance, 13, 453-464.

ARNE, D. C., MACKIE, R. A. \& JONES, S. A. 2014. The use of property-scale portable X-ray fluorescence data in gold exploration: advantages and limitations. Geochemistry: Exploration, Environment, Analysis, 14, 233.

CLARK, S., MENRATH, W., RODA, S. \& SUCCOP, P. 1999. Use of a field portable X-ray fluorescence analyser to determine the concentration of lead and other metals in 'soil' samples. American Academy of Emergency Medicine, 6, 27-32.

FAJBER, R. \& SIMANDL, G. J., 2011. Evaluation of rare earth element-enriched sedimentary phosphate deposits using portable X-ray fluorescence (XRF) instruments. British Columbia Geological Survey, Geological Fieldwork: A Summary of Field Activities and Current Research 2011, Paper 2012-1, p. 199-210.

FIGUEROA-CISTERNA, J., BAGUR-GONZÁLEZ, M. G., MORALES-RUANO, S., CARRILLO-ROSÚA, J. \& MARTÍN-PEINADO, F. 2011. The use of a combined portable $\mathrm{X}$ ray fluorescence and multivariate statistical methods to assess a validated macroscopic rock samples classification in an ore exploration survey. Talanta, $\mathbf{8 5}$, 2307-2315.

FISHER, L. A., GAZLEY, M. F., BAENSCH, A., BARNES, S. J., CLEVERLEY, J. \& DUCLAUX, G. 2014. Resolution of geochemical and lithostratigraphic complexity: a workflow for application of portable X-ray fluorescence to mineral exploration. Geochemistry: Exploration, Environment, Analysis, 14, 149.

FORSTER, N., GRAVE, P., VICKERY, N. \& KEALHOFER, L. 2011. Non-destructive analysis using PXRF: Methodology and application to archaeological ceramics. X-Ray Spectrometry, 40, 389-398.

GAZLEY, M. F., VRY, J. K., DU PLESSIS, E. \& HANDLER, M. R. 2011. Application of portable X-ray fluorescence analyses to metabasalt stratigraphy, Plutonic Gold Mine, Western Australia. Journal of Geochemical Exploration, 110, 74-80.

GLANZMAN, R. K. \& CLOSS, L. G. 2007. Field portable $\mathrm{X}$-Ray fluorescence geochemical analysis - its contribution to onsite real-time project evaluation. In:
Milkereit, B. (Ed.), Proceedings of Exploration 07: Fifth Decennial International Conference on Mineral Exploration, pp. 291-301.

HALL, G. E. M., BUCHAR, A. \& BONHAM-CARTER, G. 2013a. Quality control assessment of portable XRF analysers: development of standard operating procedures, performance on variable media and recommended uses; Phase I. CAMIRO Project 10E01, $112 \mathrm{p}$. (https://www.appliedgeochemists.org/index.php/publicati ons/other-publications)

HALL, G. E. M., PAGE, L. \& BONHAM-CARTER, G. F. 2013b. Quality control assessment of portable XRF analysers: development of standard operating procedures, performance on variable media and recommended uses; Phase II. CAMIRO Project 10E01, 218 p. (https://www.appliedgeochemists.org/index.php/publicati ons/other-publications)

HALL, G. E. M., BONHAM-CARTER, G. F. \& BUCHAR, A. 2014. Evaluation of portable X-ray fluorescence (pXRF) in exploration and mining: Phase 1, control reference materials. Geochemistry: Exploration, Environment, Analysis, 14, 99.

INNOV-X SYSTEMS INC. 2010. User manual Delta ${ }^{\mathrm{TM}}$ family: handheld XRF analysers. Document PN_103201.

JENKINS, R. 1999. X-ray fluorescence spectrometry, second edition. John Wiley \& Sons, New York.

LE VAILLANT, M., BARNES, S. J., FISHER, L. A., FIORENTINI, M. L. \& CARUSO, S. 2014. Use and calibration of portable X-Ray fluorescence analysers: application to lithogeochemical exploration for komatiitehosted nickel sulpide deposits. Geochemistry:

Exploration, Environment, Analysis, 14, 199.

MARSALA, A. F., LOERMANS, T., SHEN, S., SCHEIBE, C. \& ZEREITK R. 2011. Real-time mineralogy, lithology, and chemostratigraphy while drilling using portable energy-dispersive $\mathrm{x}$-ray fluorescence, Society of Petroleum Engineers - $73^{\text {rd }}$ European Association of Geoscientists and Engineers Conference and Exhibition 2011, 3, 2405-2411.

MERCIER-LANGEVIN, P., LAFRANCE, B., BÉCU, V., DUBÉ, B., KJARSGAARD, I. \& GUHA, J. 2014. The Lemoine auriferous volcanogenic massive sulfide deposit, Chibougamau camp, Abitibi Greenstone Belt, Quebec, Canada: geology and genesis. Economic Geology, 109, 231-269.

MOON, C. J., WHATELEY, M. K. G. \& EVANS, A. M. 2006. Introduction to mineral exploration, second edition. Blackwell Publishing

NAZAROFF, A. J., PRUFER, K. M. \& DRAKE, B. L. 2010. Assessing the applicability of portable X-ray fluorescence spectrometry for obsidian provenance research in the Maya lowlands. Journal of Archaeological Science, 37, 885-895.

PETER, J., MERCIER-LANGEVIN, P. \& CHAPMAN, J. B. 2009. Application of field-portable x-ray fluorescence spectrometers in mineral exploration, with examples from the Abitibi Greenstone Belt. Proceedings of the $24^{\text {th }}$ International Applied Geochemistry Symposium, Fredericton, New Brunswick, volume 1, p. 83-86.

PIERCEY, S. J. \& DEVINE, M. C. 2014. Analysis of powdered reference materials and known samples with a benchtop, field portable $\mathrm{x}$-ray fluorescence (pXRF) 
spectrometer: evaluation of performance and potential applications for exploration lithogeochemistry. Geochemistry: Exploration, Environment, Analysis, 14, 139.

POTTS, P. J., WILLIAMS-THORPE, O. \& WEBB, P. C. 1997. The bulk analysis of silicate rocks by portable Xray fluorescence: effect of sample mineralogy in relation to the size of the excited volume. Geostandards Newsletter, 21, 29-41

RIPLEY, B. D. \& THOMPSON, M. 1987. Regression techniques for the detection of analytical bias. The Analyst, 112, 377.

ROGERS, R., ROSS, P.-S., GOUTIER, J. \& MERCIERLANGEVIN, P. 2014. Using physical volcanology, chemical stratigraphy, and pyrite geochemistry for volcanogenic massive sulfide exploration: an example from the Blake River Group, Abitibi Greenstone Belt. Economic Geology, 109, 61-88.

ROSS, P.-S. 2010. The Baie D'Alembert showing, an example of base-metal mineralization in mafic to intermediate volcanic rocks of the Blake River Group, Abitibi Greenstone Belt, Quebec. Geological Survey of Canada, Current Research, 2010-6, 1-12.

ROSS, P.-S., BOURKE, A., FRESIA. \& DEBREIL, J.-A. 2012. Analyse multiparamétrique à haute résolution de carottes de forage dans la région de Matagami 20102012, Rapport final. Ministère des Ressources naturelles et de la Faune (Québec), report GM 66441.

ROSS, P.-S., BOURKE, A. \& FRESIA, B. 2013. A multisensor logger for rock cores: Methodology and preliminary results from the Matagami mining camp, Canada. Ore Geology Reviews, 53, 93-111.

ROSS, P.-S., BOURKE, A. \& FRESIA, B. 2014a. Improving lithological discrimination in exploration drill-cores using portable X-ray fluorescence measurements: (1) testing three Olympus Innov-X analysers on unprepared cores. Geochemistry: Exploration, Environment, Analysis, 14(2), 171.
ROSS, P.-S., BOURKE, A. \& FRESIA, B. 2014b. Improving lithological discrimination in exploration drill-cores using portable X-ray fluorescence measurements: (2) applications to the $\mathrm{Zn}-\mathrm{Cu}$ Matagami mining camp, Canada. Geochemistry: Exploration, Environment, Analysis, 14(2), 187

ROSS, P.-S., BOURKE, A., LECLERC, F. \& BOULERICE, A. 2014c. Analyse multiparamétrique à haute résolution de carottes de forage dans la région de Chibougamau 2012-2014, rapport final. Ministère des Ressources naturelles et de la Faune (Québec), report MB 2014-05, $128 \mathrm{p.}$.

SHACKLEY, M.S. 2011. X-Ray fluorescence spectrometry $(\mathrm{XRF})$ in geoarchaeology. Springer eBook, $231 \mathrm{p}$.

SIMANDL, G. J., STONE, R. S., PARADIS, S., FAJBER, R., REID, H. M. \& GRATTAN, K. 2013. An assessment of a handheld X-ray fluorescence instrument for use in exploration and development with an emphasis on REEs and related specialty metals. Mineralium Deposita, DOI: 10.1007/s00126-013-0493-0

SIMANDL, G. J., FAJBER, R. \& PARADIS, S. 2014. Portable X-ray fluorescence in the assessment of rare earth element-enriched sedimentary deposits. Geochemistry: Exploration, Environment, Analysis, 14, 161.

SLACK, J. F., SCHMIDT, J. M. \& DUMOULIN, J. A. 2004. Whole rock geochemical data for Paleozoic sedimentary rocks of the Western Brooks Range, Alaska. USGS Geological Survey Open-File Report 2004-1371,

TROMBKA, J. I., SCHWEITZER, J. \& SELAVKA, C., et al. 2002. Crime scene investigations using portable, nondestructive space exploration technology. Forensic Science International, 129, 1-9.

ZURFLUH, F. J., HOFMANN, B. A., GNOS, E. \& EGGENBERGER, U. 2011. Evaluation of the utility of handheld XRF in meteoritics. X-Ray Spectrometry, $\mathbf{4 0 ,}$ 449-463. 


\section{FIGURE CAPTIONS}

Figure 1 a): Short term instrumental drift of a Innov-X Delta premium pXRF device. NIST 2702 was continuously analysed by device B in mining plus mode for several hours. Results were normalized to the first measurement and a nine-points moving average was applied. Offsets of increments of 0.1 were applied to each element to separate the trend lines. b): Long term instrumental drift of the same device. Ten measurements were made on NIST 2702 periodically over a year and averaged. Results were normalized to the mean of all measurements. Offsets of increments of 0.1 were applied to each element to separate the trend lines.

Figure 2: Results of a precision and beam time test on the Delta-A device in soil mode on a rhyolite core sample (MD-01-01): (a) major elements; (b) trace elements. The relative standard deviations are calculated from a series of 31 measurements on the same spot on the core.

Figure 3: Results of a precision and beam time test on the Delta-A device in soil mode on a basaltic andesite core sample (HEB-02-08): (a) major elements; (b) trace elements. The relative standard deviations are calculated from a series of 31 measurements on the same spot on the core.

Figure 4: Comparison of Delta-A results in soil mode with laboratory geochemistry for rock core samples (triangles) and powdered samples (squares). The pXRF data are averages of series of 33 to 63 measurements made on 20 samples from the Hébécourt and Chibougamau regions. The reverse of the linear regressions correspond to the corrections that should be applied to the pXRF data to obtain more accurate values. The dotted line on each graph represents the 1:1 slope.

Figure 5: Comparison of Delta-B results in mining plus mode with laboratory geochemistry for rock core samples (triangles) and powdered samples (squares). The pXRF data are averages of series of 31 to 63 measurements made on 27 samples from the Matagami, Hébécourt and Chibougamau regions. The reverse of the linear regressions correspond to the corrections that should be applied to the pXRF data to obtain more accurate values. The dotted line on each graph represents the 1:1 slope.

Figure 6: Venn diagram representing the three groups of correctible elements: (1) elements better determined in situ on rock cores with respect to accuracy, (2) elements better determined on powders and (3) elements showing similar results regardless of the media. The diagram also shows the elements that are detected but not correctible. The following elements and oxides are determined in mining plus mode for best results: $\mathrm{Al}_{2} \mathrm{O}_{3}, \mathrm{CaO}, \mathrm{Fe}_{2} \mathrm{O}_{3}, \mathrm{MgO}, \mathrm{MnO}$, $\mathrm{Ni}, \mathrm{SiO}_{2}$ and $\mathrm{Zr}$. The following elements and oxides are determined in soil mode for best results: $\mathrm{Cr}, \mathrm{K}_{2} \mathrm{O}, \mathrm{Nb}, \mathrm{Rb}$, $\mathrm{Sb}, \mathrm{TiO}_{2}$ and $\mathrm{Y}$.

Figure 7: Results of a 'sample precision' test with the Delta-A device in soil mode on a basaltic andesite core sample (HEB-02-08): a) major elements; b) trace elements. The relative standard deviations were calculated from a series of 42 measurements, each taken on a different spot on the sample, after moving averages of 1 to 29 points were calculated. The best compromise between improvements in precision and analysis time (i.e. number of measurements averaged) seems to be between five and seven points. 
a

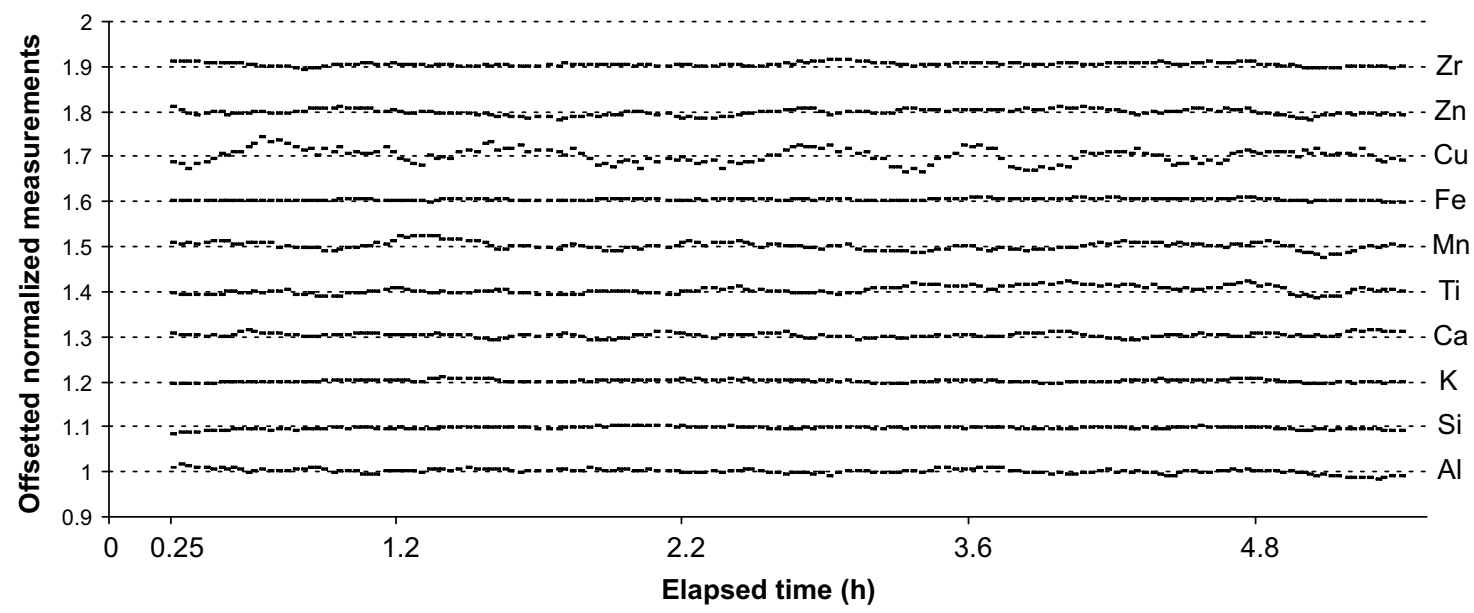

b




a

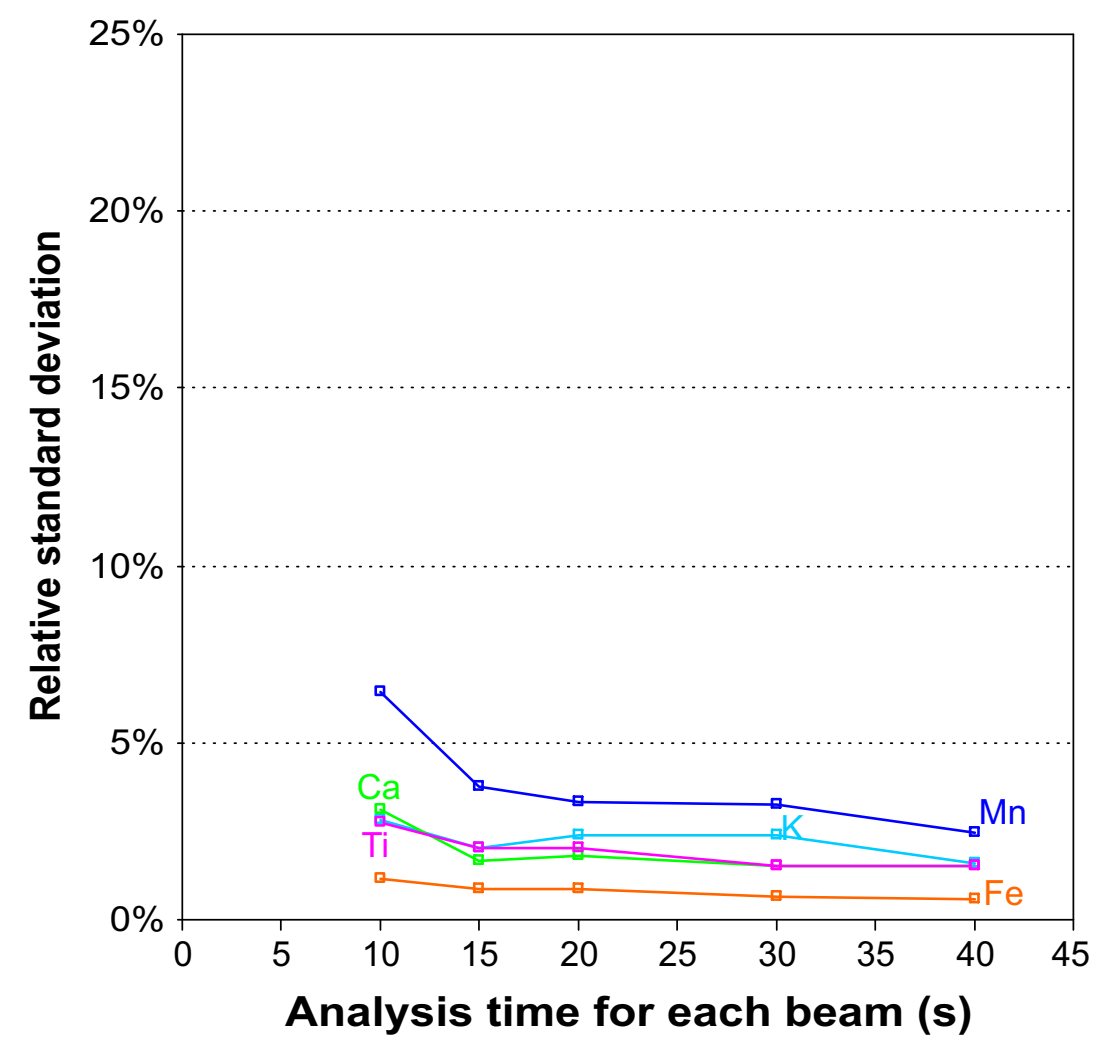

b




a

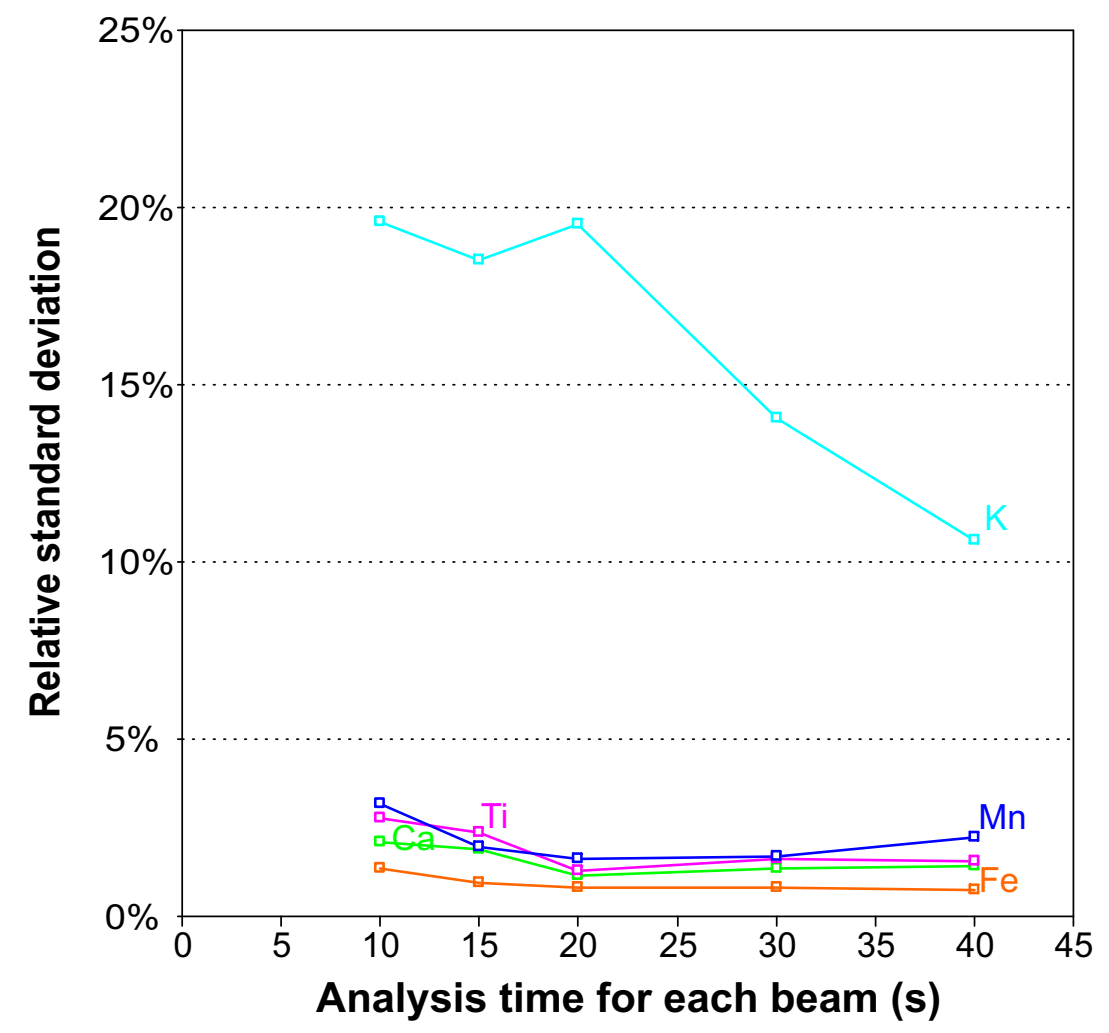

b

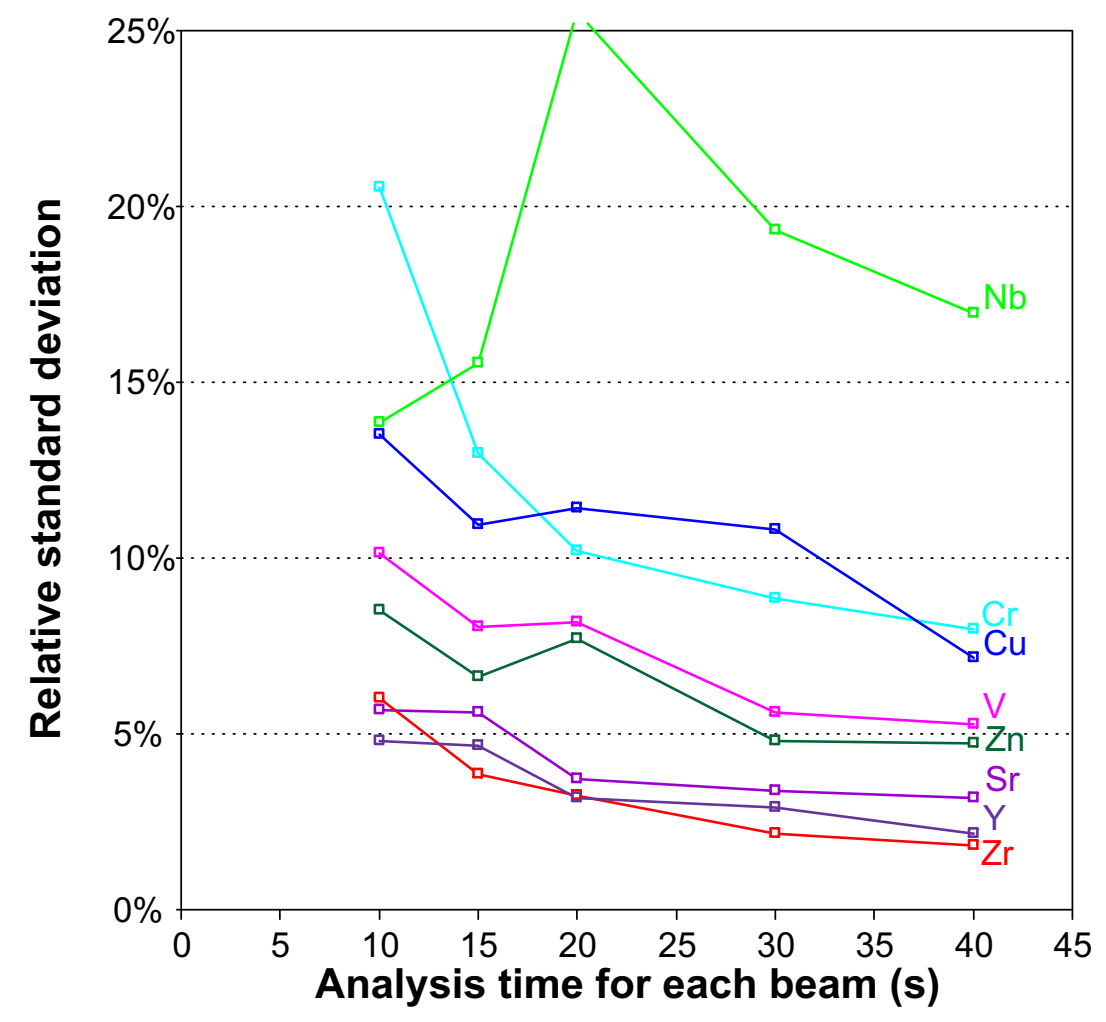


a

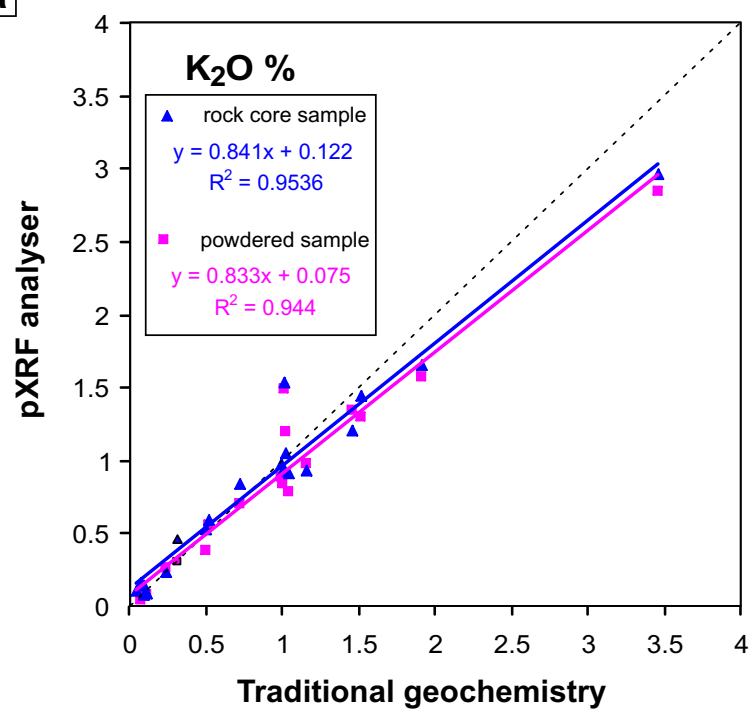

C



e

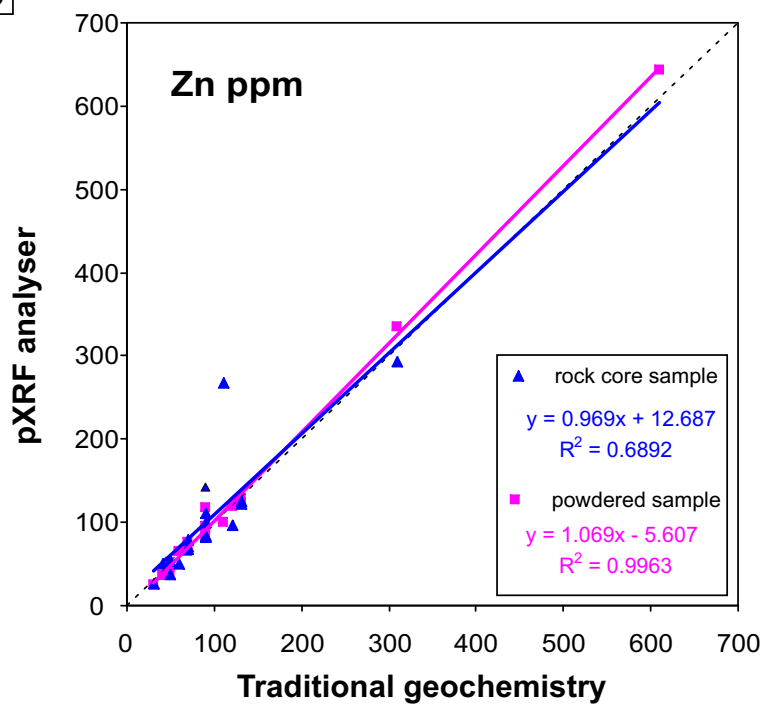

b

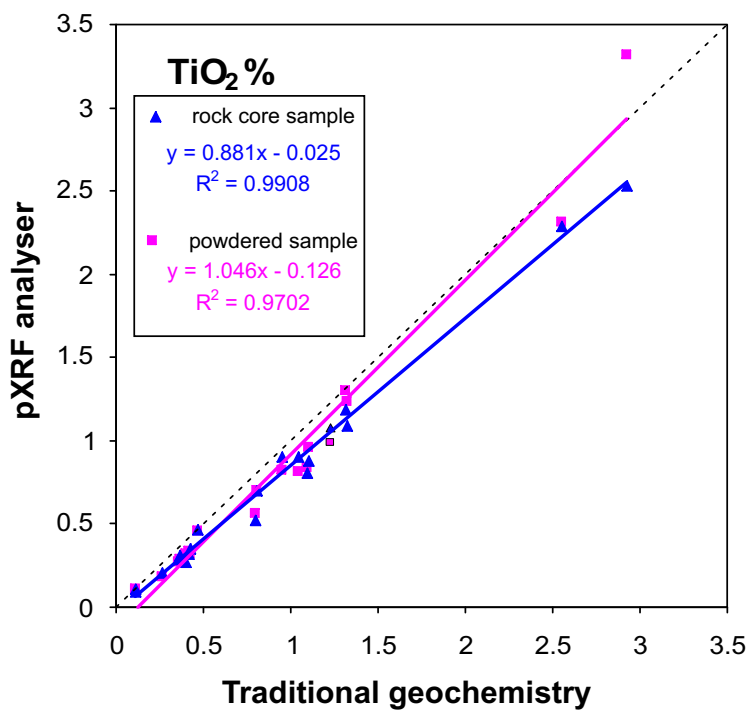

d



$\mathbf{f}$

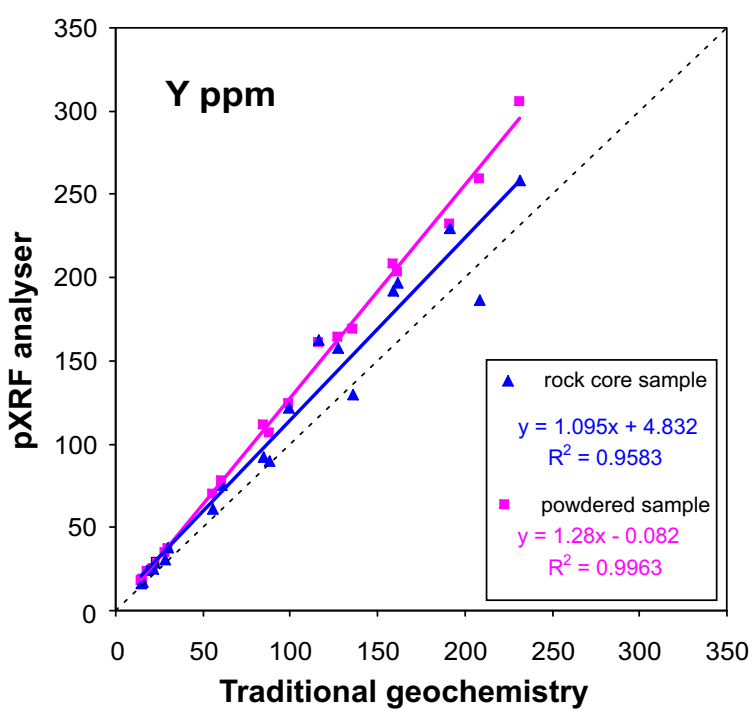


a

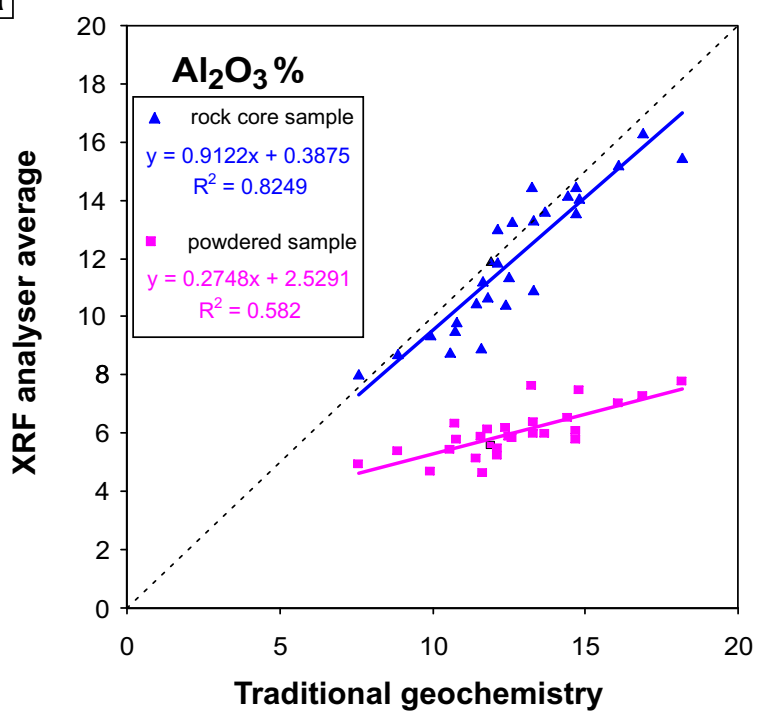

C



e



b



d

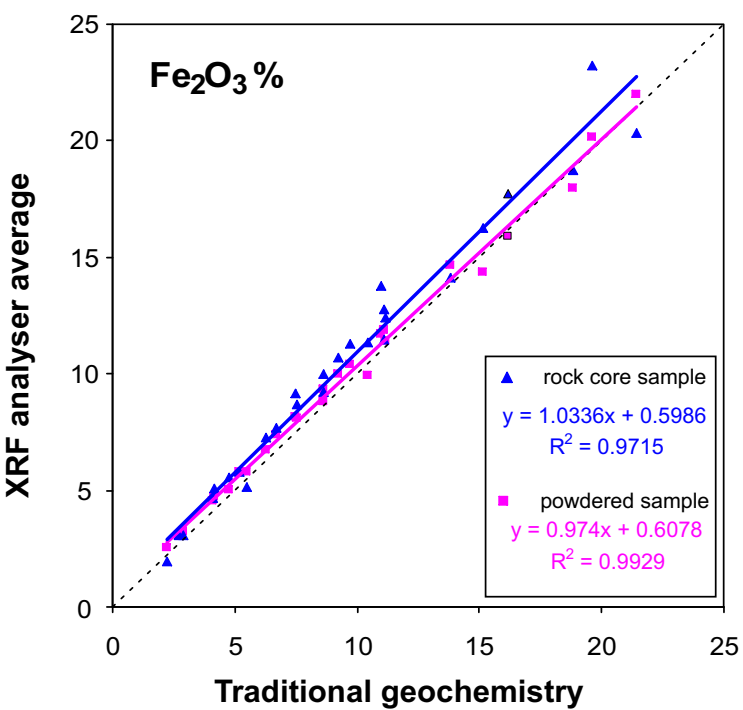

f

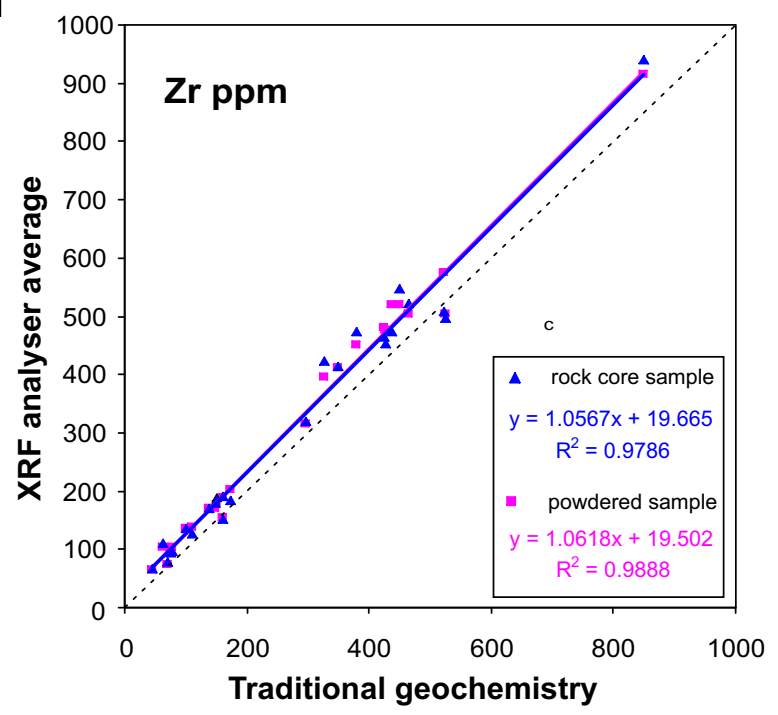




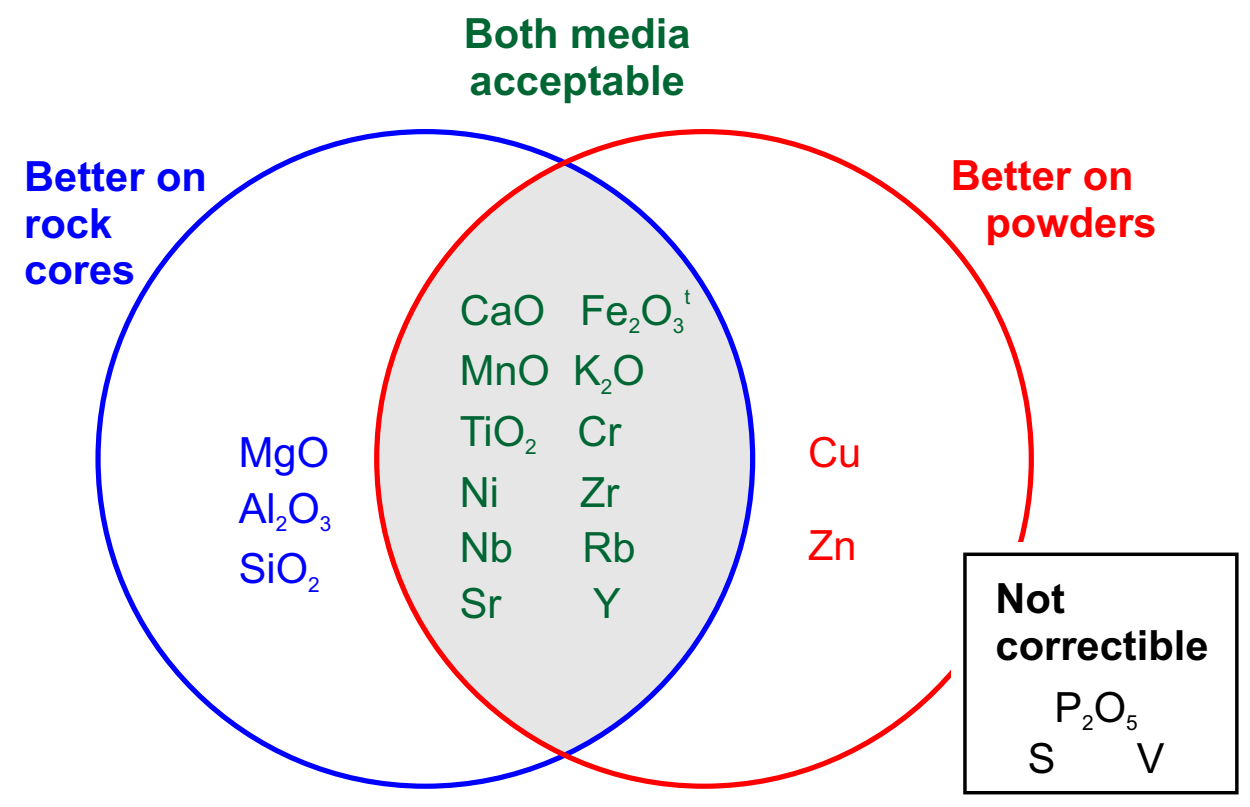

Bourke \& Ross, GEEA, Fig. 6 

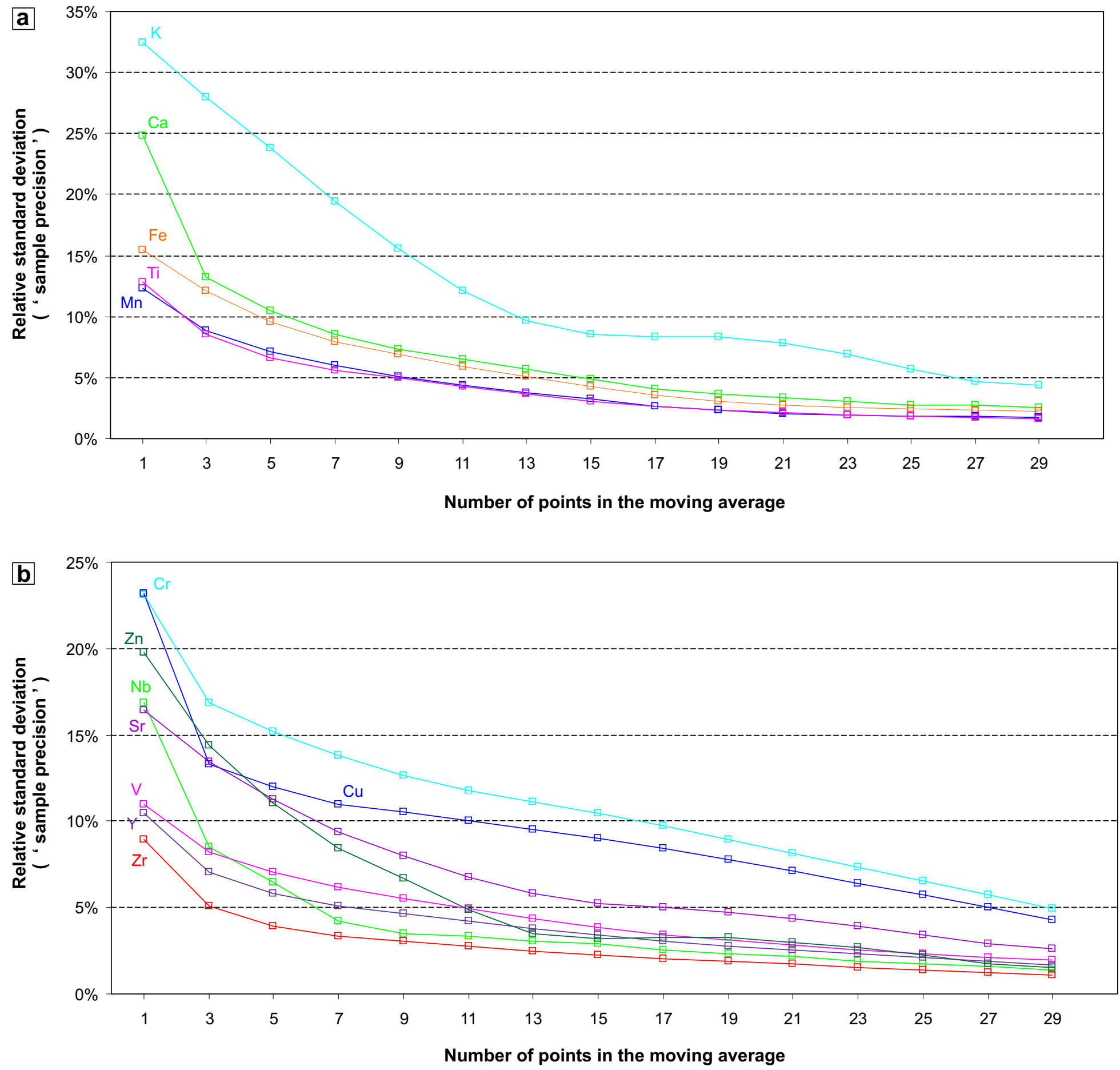